\title{
Fuzzy Logic Speed Control Stability Improvement of Lightweight Electric Vehicle Drive
}

\author{
Abdelfatah Nasri ${ }^{\dagger}$, Abdeldjabar Hazzab*, Ismail.K Bousserhane*, \\ Samir Hadjeri** and Pierre Sicard ${ }^{* * *}$
}

\begin{abstract}
To be satisfied with complex load condition of electric vehicle, fuzzy logic control (FLC) is applied to improve speed response and system robust performance of induction traction machine based on indirect rotor field orientation control. The proposed propulsion system consists of two induction motors (IM) that ensure the drive of the two back driving wheels of lightweight electric vehicle by means the vehicle used for passenger transportation. The electronic differential system ensures the robust control of the vehicle behavior on the road. It also allows controlling, independently, every driving wheel to turn at different speeds in any curve. Our electric vehicle fuzzy inference system control's simulated in Matlab SIMULINK environment, the results obtained present the efficiency and the robustness of the proposed control with good performances compared with the traditional PI speed control, the FLC induction traction machine presents not only good steady characteristic, but with no overshoot too.
\end{abstract}

Keywords: Electric vehicle, Electronic differential, Induction motor, Lightweight electric vehicle, Fuzzy logic speed control

\section{Introduction}

Electric vehicles (EVs) Electric vehicles (EVs) are developing fast during this decade due to drastic issues on the protection of environment and the shortage of energy sources. While commercial hybrid cars have been rapidly exposed on the market, fuel-cell-powered vehicles are also announced to appear in 5-10 years. Researches on the power propulsion system of EVs have drawn significant attention in the automobile industry and among academics. EVs can be classified into various categories according to their configurations, functions or power sources. Pure EVs do not use petroleum, while hybrid cars take advantages of energy management between gas and electricity [1].

Indirectly driven EVs are powered by electric motors through transmission and differential gears, while directly driven vehicles are propelled by in-wheel or, simply, wheel motors [2]. The basic vehicle configurations of this research has two directly driven wheel motors installed and operated inside the driving wheels on a pure EV. These wheel motors can be controlled independently and have so quick and accurate response to the command that the vehicle chassis control or motion control becomes more stable and robust, compared to indirectly driven EVs. Like most research on the torque distribution control of wheel motor,

$\dagger \quad$ Corresponding Author : Bechar University, B.P 417 Bechar (08000), Algeria

* Bechar University, B.P 417 Bechar (08000), Algeria

** University of Djillali Liabes Electrical Engineering Department, B.P 98 Sidi Bel-Abbes (22000), Algeria

*** Research group on industrial Electronics University of Quebec in Trois-Rivieres, Trois-Rivieres

Received : May 25, 2009; Accepted : December 21, 2009 wheel motors [3] proposed a dynamic optimal tractive force distribution control for an EV driven by four wheel motors, thereby improving vehicle handling and stability.

The researchers assumed that wheel motors were all identical with the same torque constant; neglecting motor dynamics the output torque was simply proportional to the input current with a prescribed torque constant.

The reminder of this paper is organized as follows: Section II reviews the principle components of the Electric traction chain with their equations model. Section III shows the fuzzy logic control strategy of the electric vehicle motorization. The proposed structure of the studied propulsion system is given in the section IV. Section V gives some simulation results of the different studied cases. Finally, the conclusion is drawn in section VI.

\section{Electric Traction System Elements Modeling}

Fig. 1 represents the general diagram of an electric traction system using an induction motor (IM) supplied by voltage inverter [4], [8].

\subsection{Energy Source}

The battery considered in this paper is of the LithiumIon [9], the battery current is calculated by:

$$
I_{b a t}=\frac{V_{o c}-\sqrt{V_{o c}^{2}}-4 \cdot\left(R_{\mathrm{int}}+R_{t}\right) \cdot P_{b}}{2 \cdot\left(R_{\mathrm{int}}+R_{t}\right)}
$$

where : 


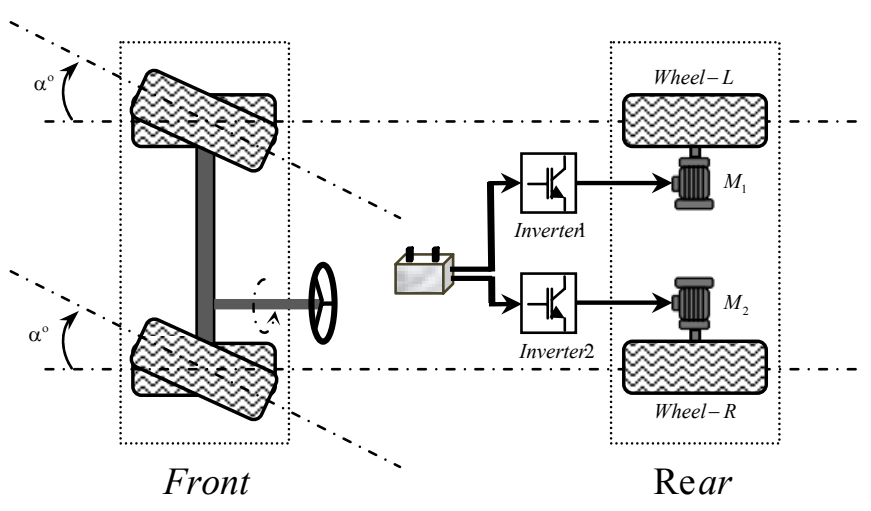

Fig. 1. Electrical traction chain.

$P_{b}:$ Output power of battery,

$R_{\text {int }}$ : Internal resistance,

$V_{o c}$ : The open circuit voltage,

$R_{t}$ : The terminal voltage of the battery

\subsection{Static Converter}

In this electric traction system, we use a three balanced phases of alternating current inverter with variable frequency from the current battery [4].

$$
\left[\begin{array}{l}
v_{a n} \\
v_{b n} \\
v_{c n}
\end{array}\right]=\frac{U_{d c}}{2}\left[\begin{array}{ccc}
2 & -1 & -1 \\
-1 & 2 & -1 \\
-1 & -1 & 2
\end{array}\right]\left[\begin{array}{l}
S_{a} \\
S_{b} \\
S_{c}
\end{array}\right]
$$

The $S_{i}$ are logical switches obtained by comparing the control inverter signals with the modulation signal.

\subsection{Traction Motor}

The used motorization consist of three phase induction motor (IM) supplied by a voltage inverter controlled by Pulse Width Modulation (PWM) techniques. The dynamic model of three-phase, Y-connected induction motor can be expressed in the d-q synchronously rotating frame as [4], [6], [13]:

$$
\left\{\begin{array}{l}
\frac{d i_{d s}}{d t}=\frac{1}{\sigma \cdot L_{s}} \cdot\left(-\left(R_{s}+\left(\frac{L_{m}}{L_{r}}\right)^{2} \cdot R_{r}\right) i_{d s}+\sigma \cdot L_{s} \cdot \omega_{e} \cdot i_{q s}+\frac{L_{m} \cdot R_{r}}{L_{r}^{2}} \cdot \phi_{d r}+\frac{L_{m}}{L_{r}} \cdot \phi_{q r} \cdot \omega_{r}+V_{d s}\right) \\
\frac{d i_{q s}}{d t}=\frac{1}{\sigma \cdot L_{s}} \cdot\left(-\sigma \cdot L_{s} \cdot \omega_{e} \cdot i_{d s}-\left(R_{s}+\left(\frac{L_{m}}{L_{r}}\right)^{2} \cdot R_{r}\right) i_{q s}-\frac{L_{m}}{L_{r}} \cdot \phi_{d r} \cdot \omega_{r}+\frac{L_{m} \cdot R_{r}}{L_{r}^{2}} \cdot \phi_{q r}+V_{q s}\right) \\
\frac{d \phi_{d r}}{d t}=\frac{L_{m} \cdot R_{r}}{L_{r}} \cdot i_{d s}-\frac{R_{r}}{L_{r}} \cdot \phi_{d r}+\left(\omega_{e}-\omega_{r}\right) \phi_{d r} \\
\frac{d \phi_{q r}}{d t}=\frac{L_{m} \cdot R_{r}}{L_{r}} \cdot i_{q s}-\left(\omega_{e}-\omega_{r}\right) \cdot \phi_{d r}-\frac{R_{r}}{L_{r}} \cdot \phi_{q r} \\
\frac{d \omega_{r}}{d t}=\frac{3}{2} \frac{P^{2} \cdot L_{m}}{L_{r} \cdot J} \cdot\left(i_{q s} \cdot \phi_{d r}-i_{d s} \cdot \phi_{q r}\right)-\frac{f_{c}}{J} \cdot \omega_{r}-\frac{P}{J} \cdot T_{l}
\end{array}\right.
$$

Where $\sigma$ is the coefficient of dispersion and is given by:

$$
\sigma=1-\frac{L_{m}^{2}}{L_{s} L_{r}}
$$

$$
\begin{array}{lc}
L_{s}, L_{r}, L_{m} & \text { stator, rotor and mutual inductances; } \\
R_{s}, R_{r} & \text { stator and rotor resistances; } \\
\omega_{e}, \omega_{r} & \text { electrical and rotor angular frequency; } \\
\omega_{s l} & \text { Slip frequency }\left(\omega_{e}-\omega_{r}\right) ; \\
\tau_{r} & \text { Rotor time constant }\left(L_{r} / R_{r}\right) ; \\
P & \text { Pole pairs }
\end{array}
$$

\subsection{Electric Vehicle Mechanical Load's}

The vehicle is considered as a load is characterized by many torques which are mostly considered as resistive torques [4]-[5], [12], [15], [17]-[18]. The different torques includes:

The vehicle inertia torque defined by the following relationship:

$$
T_{\text {in }}=J_{v} \cdot \frac{d w_{v}}{d t}
$$

The aerodynamics torque is:

$$
T_{\text {aero }}=\frac{1}{2} \rho S \cdot T_{x} \cdot R_{r}^{3} \cdot w_{r}^{2}
$$

The slope torque is :

$$
T_{\text {slope }}=M g \cdot \sin \alpha
$$

The maximal torque of the tire which can be opposed to the motion has the following expression:

$$
T_{\max }=M g f_{r} \cdot R_{r}
$$

We obtain finally the total resistive torque:

$$
T_{v}=T_{\text {slope }}+T_{\text {tire }}+T_{\text {aero }}
$$

\subsubsection{Gear}

The speed gear ensures the transmission of the motor torque to the driving wheels. The gear is modelled by the gear ratio, the transmission efficiency and its inertia.

The mechanical equation is given by:

$$
J_{e} \frac{d w_{m}}{d t}+f w_{m}=p\left(T_{e m}-T_{r}\right)
$$

with:

$$
T_{r}=\frac{1}{\eta N_{\text {red }}} T_{v}
$$




$$
J_{e}=J+\frac{J_{v}}{\eta N_{r e d}^{2}}
$$

The modelling of the traction system allows the implementation of some controls such as the vector control and the speed control in order to ensure the globally system stability.

\section{Fuzzy Logic Speed Control Strategy}

The main objective To be fitted with complex load environment of electric vehicles, induction traction machine needs higher specific power, efficiency and rotation speed than common industrial machines. Therefore, dimension of stator and rotor iron core of induction traction machine is smaller, and wound specific current is larger. Although small resistance and inductance is helpful to use voltage, it also produces large current wave and easy saturation magnetic circuit, which results in controlling machine difficultly.

Fuzzy logic control (FLC) has been applied to induction machine drive, which makes drive less sensitive to parameter variation [1], [4]-[5], [7], [16] and more efficient [6], [10]-[11], [16], In this paper, the fuzzy logic control drive system of induction traction machine is presented, on which the fuzzy logic is applied to Improve machine's speed control performance to start up quickly and smoothly.

\subsection{Design of Fuzzy Logic Speed Regulator}

According to indirect field orientation mathematical model of induction machine [4] speed control drive system based on dual PI current regulators is showed in figure.6.

This fuzzy logic control is nonlinear regulator, which Control the torque current quantity adaptive to pedal input by motor speed error and its difference.

$$
\begin{array}{r}
e(k)=w_{r}(k)-w_{r e f} \\
e(k)=\frac{e(k)-e(k-1)}{\Delta t}
\end{array}
$$

Where $\Delta t$ is sample cycle, $w_{r}(k)$ is real time sample value, and $w_{\text {ref }}$ is reference value of motor speed.

Generally, a fuzzy logic controller needs input, output variables and inference, which is a term set based on rule base. (13) and (14) determine the input variables. Clearly, Output variable is also determined by fuzzy logic speed regulator. Because of no particular theory in designing a best rule-base on terms, fuzzy inference [1], [4]-[5], [7], [16]based on rule base is artificial from the designer's experiences and experts' knowledge. More terms, and more rules will result in more

Complicated fuzzy inference. In the proposed fuzzy logic control, a five-term set \{negative big (NB), negative small (NS), zero (ZE), positive small (PS), positive big
(PB) is applied to defining input and output linguistic variable.

This present fuzzy logic control is showed in Fig. 5. In this figure, ke, kde, and ku are gains of the speed error e, speed error difference and torque current variety output control $\mathbf{U}$ here $\mathbf{U}$ means the stator current estimed.

A fuzzy set can convert fuzzy input-out term into quantitative description, which is called fuzzification.

Meanwhile, membership function and its discretization are first. to be qualified. The corresponding quantitative input field is defined as $\{-4,-2,0,2,4\}$ and $\{-4,-2,0,2,4\}$ as it shown in Fig. 2,3 .

And the output field is selected as $\{-4 .-1,0,1,4\}$. The proposed membership function is figured as Fig. 4 .

Building fuzzy logic rule is the key step in the improvement of system performance, which is a set of Statements as $\{$ IF. . . , THEN . . . $\}$. For instance, IF input1 is NB and input 2 is NB, THEN output is PB. These rules can be produced by rule 'base as Table 1. After rules finished, this fuzzy inference and defuzzification can be doned, which is based on the min-max method (Mamdani) [1], [4]-[5], [7], [16]. By off-line calculation and regulation, this fuzzy logic inference rules is showed in the Table 1. However, one can easily design a good fuzzy logic by MATLAB tools.

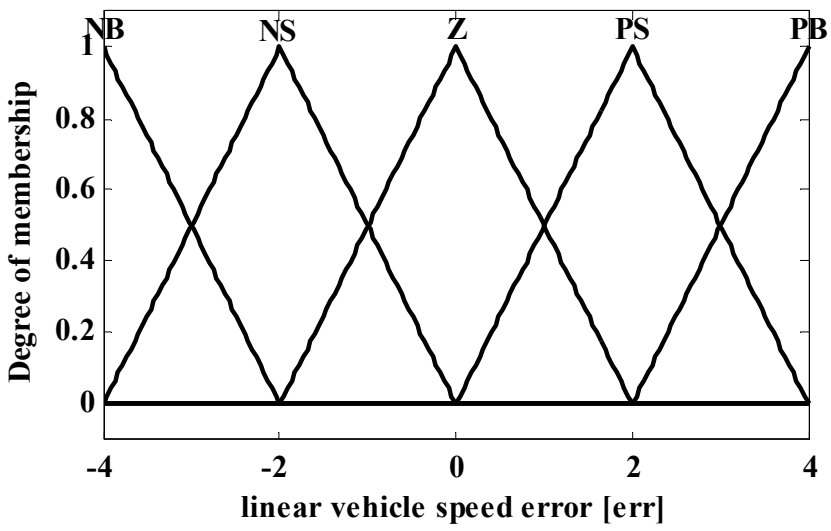

Fig. 2. Speed error derivate membership functions.

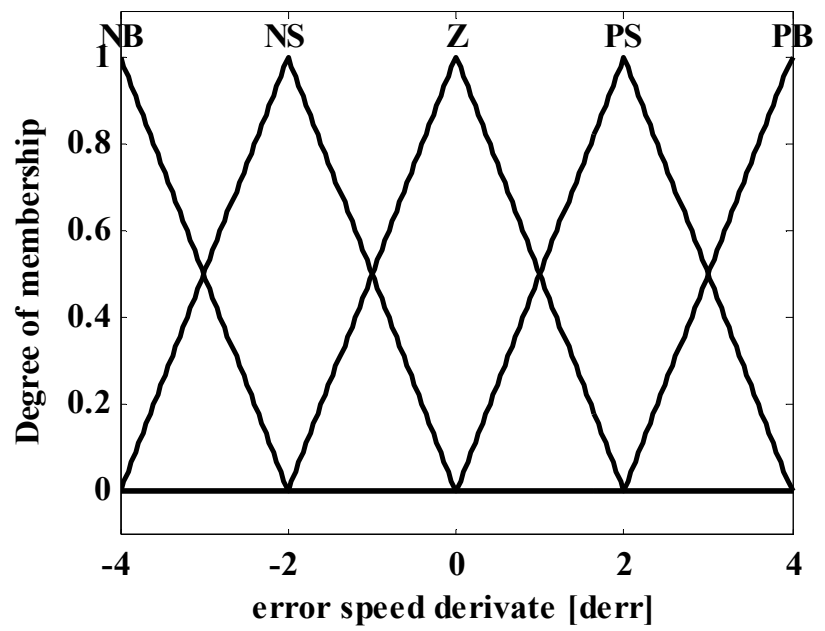

Fig. 3. Speed error membership functions. 


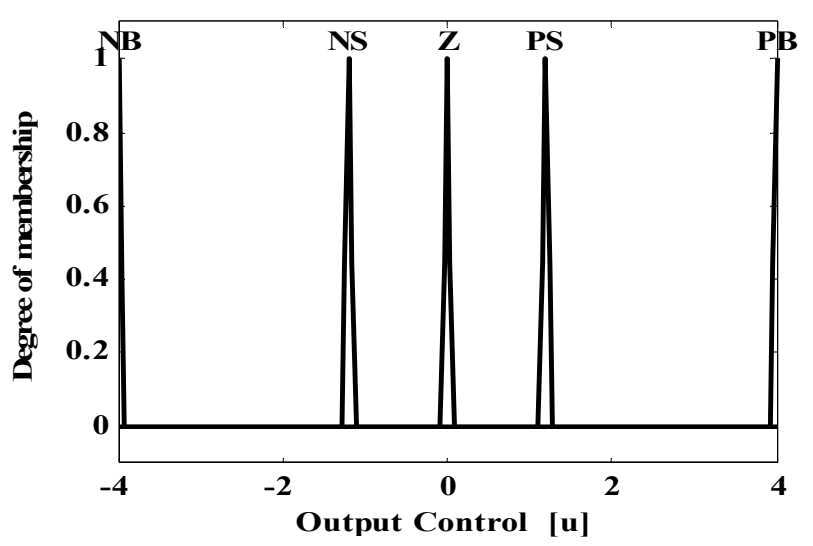

Fig. 4. output control membership functions.

Table 1. Fuzzy inference rules

\begin{tabular}{c|c|c|c|c|c|c}
\hline \multicolumn{2}{c|}{$u(t)$} & \multicolumn{5}{c}{$e(t)$} \\
\cline { 3 - 7 } \multicolumn{1}{c|}{} & NB & NS & Z & PS & PB \\
\hline \multirow{4}{*}{$\operatorname{de}(t)$} & NB & NB & NB & NS & NS & Z \\
\cline { 2 - 7 } & NS & NB & NS & NS & Z & PS \\
\cline { 2 - 7 } & Z & NS & NS & Z & PS & PS \\
\cline { 2 - 7 } & PS & NS & Z & PS & PS & PB \\
\cline { 2 - 7 } & PB & Z & PS & PS & PB & PB \\
\hline
\end{tabular}

Where : e $(\mathrm{t})$ and $\mathrm{de}(\mathrm{t})$ are the speed error and the error speed variation respectively.

The Fig. 5 shows the Fuzzy logic controller structure.

\section{Structure of the Studied System}

The general scheme of the driving wheels control is represented by Fig. 6 and 8. It's an electric vehicle which the back driving wheels are controlled independently by two IM. The reference blocks must provide the speed references of each motor taking into consideration information from the different sensors.

The Fig. 7 shows the electronic differential geometry of the vehicle studied system.

\section{Speed References Computation}

Fig. 1 illustrates the implemented system (electric and mechanical components) in the Matlab-Simulink environment. It should be noted that the two inverters share the same dc bus whose voltage is supposed to be stable. Regenerative braking is not taken into account in this paper. The proposed control system principle could be summarized as follows: 1) A speed Fuzzy logic control is used to control each motor torque; 2) The speed of each rear wheel is controlled using speed difference feedback. Since the two rear wheels are directly driven by two separate motors, the speed of the outer wheel will need to be higher than the speed of the inner wheel. during steering maneuvers (and vice-versa). This condition can be easily met if the speed estimator is used to sense the angular speed of the steering wheel. The common reference speed $w_{\text {ref }}$ is then set by the accelerator pedal command as it shown on Fig. 7. The actual reference speed for the left drive $w_{\text {ref-left }}$ and the right drive $w_{\text {ref-right }}$ are then obtained by adjusting the common reference speed $w_{\text {ref }}$ using the output signal from the fuzzy logic speed estimator. If the vehicle is turning right, the left wheel speed is increased and the right wheel speed remains equal to the common reference speed $w_{\text {ref }}$. If the vehicle is turning left, the right wheel

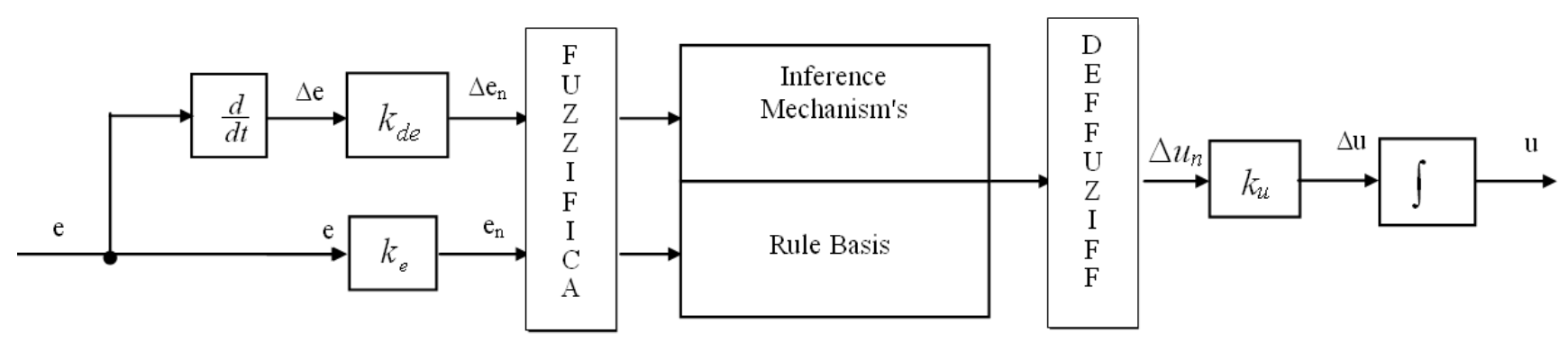

Fig. 5. Fuzzy Logic Controller Structure (FLC).

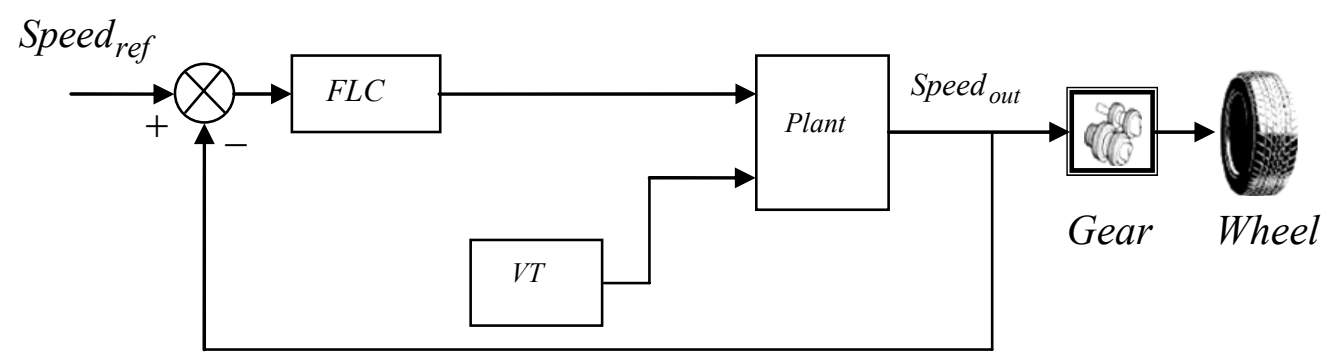

Fig. 6. The driving wheels control system. 


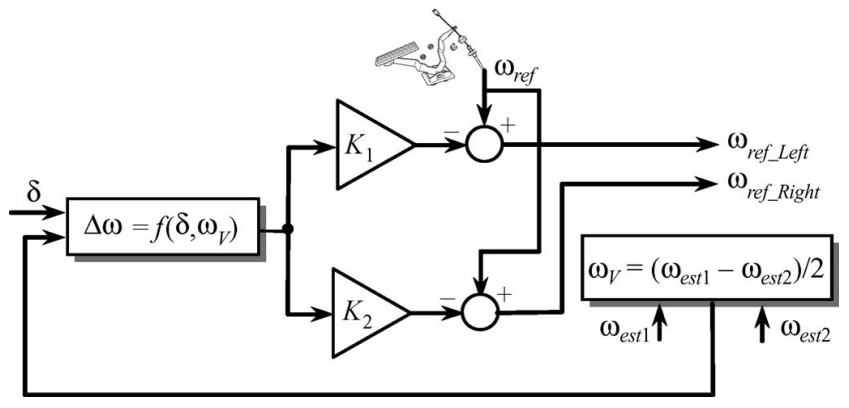

Fig. 7. Block diagram of the electric differential system.

speed is increased and the left wheel speed remains equal to the common reference speed $\omega$ ref [8], [15], [17]-[19].

Usually, a driving trajectory is adequate for an analysis of the vehicle system model. We therefore adopted the Ackermann-Jeantaud steering model[17], as it is widely used as a driving trajectory. In fact, the Ackermann steering geometry is a geometric arrangement of linkages in the steering system of a car or other vehicles designed to solve the problem of wheels on the inside and outside of a turn needing to trace out circles of different radii. Modern cars do not use pure Ackermann-Jeantaud steering, partly because it ignores important dynamic and compliant effects, but the principle is sound for low speed maneuvers [17][19]. It is illustrated in Fig. 1. From this model, the following characteristic can be calculated:

$$
R_{w}=\frac{L_{w}}{\tan \delta}
$$

Where $\delta$ is the steering angle. Therefore, the linear speed of each wheel drive is given by :

$$
\begin{gathered}
V_{1}=w_{v}\left(R_{w}-\frac{d_{w}}{2}\right) \\
V_{2}=w_{v}\left(R_{w}+\frac{d_{w}}{2}\right)
\end{gathered}
$$

Where: $L_{w}$ is the distance between front and rear wheels and $R_{w}$ is the wheel radius and $d_{w}$ is the distance between two driving heels and $\delta$ the steering wheel angle.[4], [15], [17] and their angular speed by:

$$
\left\{\begin{array}{c}
W_{e s t 1}=\frac{L_{w}-\left(\frac{d_{w}}{2}\right) \tan \delta}{L_{w}} w_{v} \\
W_{e s t 2}=\frac{L_{w}+\left(\frac{d_{w}}{2}\right) \tan \delta}{L_{w}} w_{v}
\end{array}\right.
$$

Where $w_{v}$ is the vehicle angular speed according to the center of turn. then

The difference between wheel drive angular speeds is

$$
\Delta w=w_{e s t 1}-w_{e s t 2}=-\frac{d_{w} \tan \delta}{L_{w}} w_{v}
$$

and the steering angle indicates the trajectory direction

$$
\left\{\begin{array}{l}
\delta>0 \Rightarrow \text { Turn Left } \\
\delta=0 \Rightarrow \text { Straight ahead } \\
\delta<0 \Rightarrow \text { Turn Right }
\end{array}\right.
$$

In accordance with the above described equation, figure 8 shows the electric differential system block diagram as used for simulations, where $\mathrm{K} 1=1 / 2$ and $\mathrm{K} 2=-1 / 2$.

Where: VT is the Vehicle resistive torque and FLC the fuzzy logic speed controller

The proposed propulsion system structure is similar to that of multi-converters multi-machines system [4], it is defined as a system composed by several electric drives mechanically coupled. The Fig. 8 represents the electric vehicle (EV) driving wheels system, where MR and ML represent the right driving motor and left driving motor respectively.

The Fig. 9 shows the vehicle geometry of the studied system.

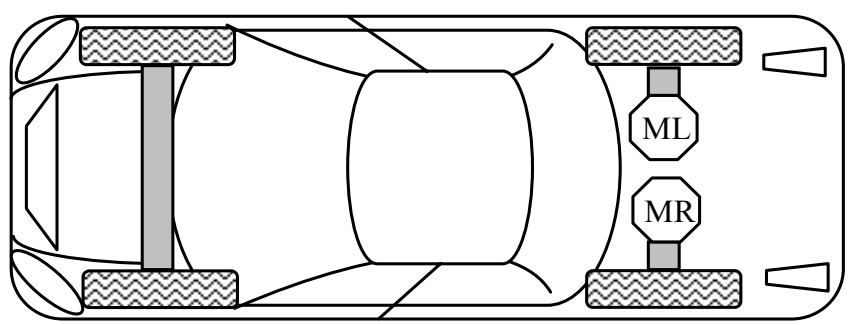

Fig. 8. the electric vehicle (EV) driving wheels system.

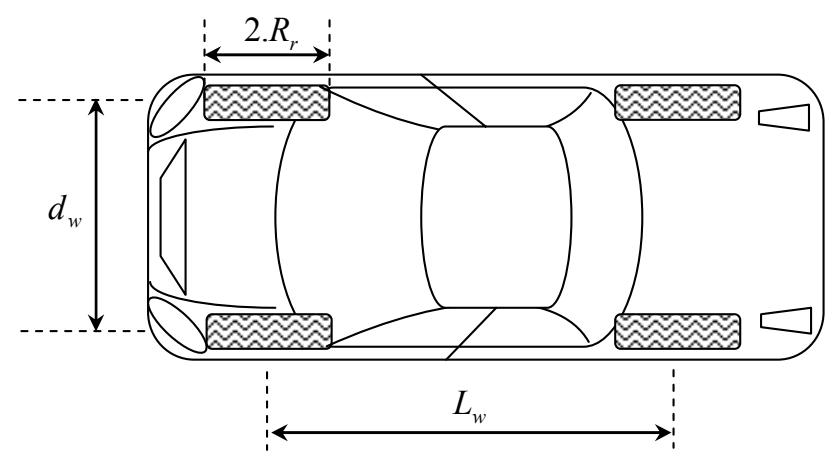

Fig. 9. The vehicle geometry.

\section{Simulation Results}

In order to characterize the driving wheel system behavior, simulations were carried using the model of Fig. 6. They show vehicle speed variation for PI controllers and the Fuzzy Logic controller. 
In order to simplify the control algorithm and improve the control loop robustness, instead of using classical control, we use the Fuzzy logic control [1], [4]-[5], [7], [10][11], [16]. The advantage of this control is its robustness, its capacity to maintain ideal trajectories for two wheels control independently and ensure good disturbances rejections with no overshoot and stability of vehicle perfected ensured with the speed variation and less error speed.

To compare the effect of disturbances on the vehicle speed in the cases of two types of controls, Fig. 10.1 and Fig. 10.2 shows the system response in two cases (Fuzzy Logic and the PI classical control). We can summaries the vehicle speed results in the table number2:

From the Fig.10.1 and Fig. 10.2 and the table we can say that: the effect of the disturbance is neglected in the

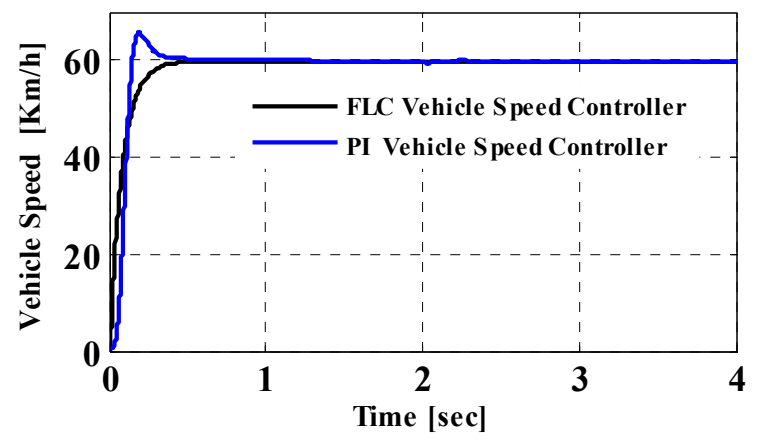

Fig. 10.1. Vehicle speed for two controller cases.

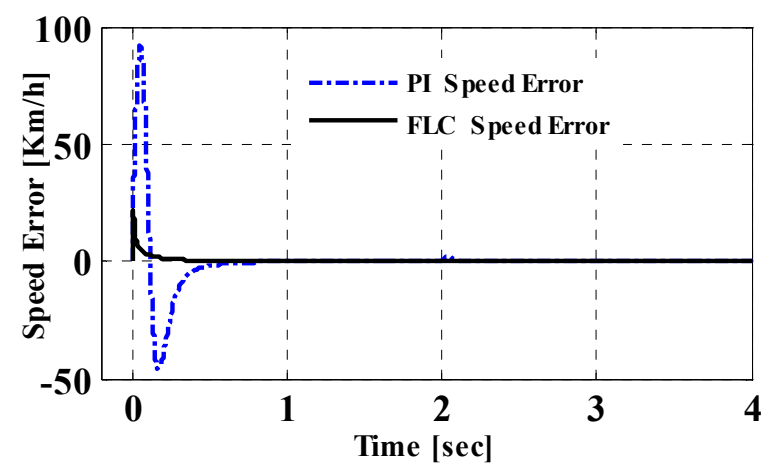

Fig. 10.2. vehicle Error speed variations for two controller cases.

Where: FUZZIFICA is the Fuzzification process and DEFFUZIFF is the Deffuzification process.

Table 2. Performances of the PI and FLC controllers in the linear speed response

\begin{tabular}{c|c|c|c|c}
\hline Results & $\begin{array}{c}\text { Rising } \\
\text { time } \\
{[\mathrm{Sec}]}\end{array}$ & $\begin{array}{c}\text { Overtaking } \\
{[\%]}\end{array}$ & $\begin{array}{c}\text { Steady } \\
\text { state } \\
\text { error [\%] }\end{array}$ & $\begin{array}{c}\text { Disturbance } \\
\text { application } \\
\text { time (slope } \\
\text { torque) }\end{array}$ \\
\hline PI & 0.1564 & 11.6666 & 0 & At 2 Sec \\
\hline FLC & 0.6000 & 0 & 0 & At 2 Sec \\
\hline
\end{tabular}

case of the Fuzzy controllers. It appears clearly that the classical control with PI controller is easy to apply.

However the control with the Fuzzy Logic controller offers better performances in both of the overshoot control and the tracking error.

In addition to these dynamic performances, it respects the imposed constraints by the driving system such as the robustness of parameter variations.

\subsection{Case of Straight Way}

- Flat road with $10 \%$ slope at $60 \mathrm{~km} / \mathrm{h}$ speed at time $2 \mathrm{sec}$

In this test, the system is submitted to the same speed step. The driving wheels speeds stay always the same and the road slope does not affect the control of the wheel and the Fuzzy control act immediately to reduce the speed error caused by the slope road constraints and give's more and more efficiency to the electronic differential output references. We can say the slope sensitize the motorization to develop efforts in order to satisfy the electric traction chain demand.

The system behaviour of theses speeds is illustrated by Figs. 11.4, Fig. 11.2. and 11.3 describe the electromagnetic torque and driving forces variations. The resistant torques is shown in Fig. 11.1.

All the results of his case are summaries in Table 3 and 4

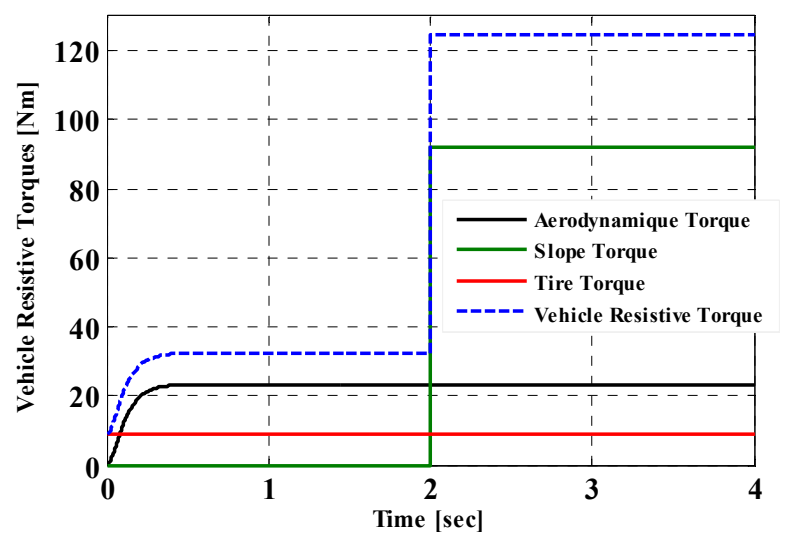

Fig. 11.1. Vehicle wheel speed.

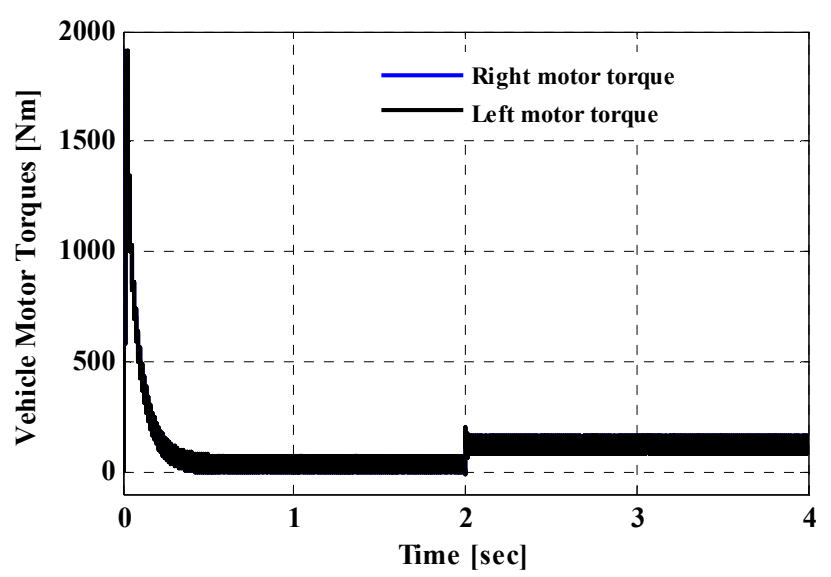

Fig. 11.2. Vehicle Driving Forces. 


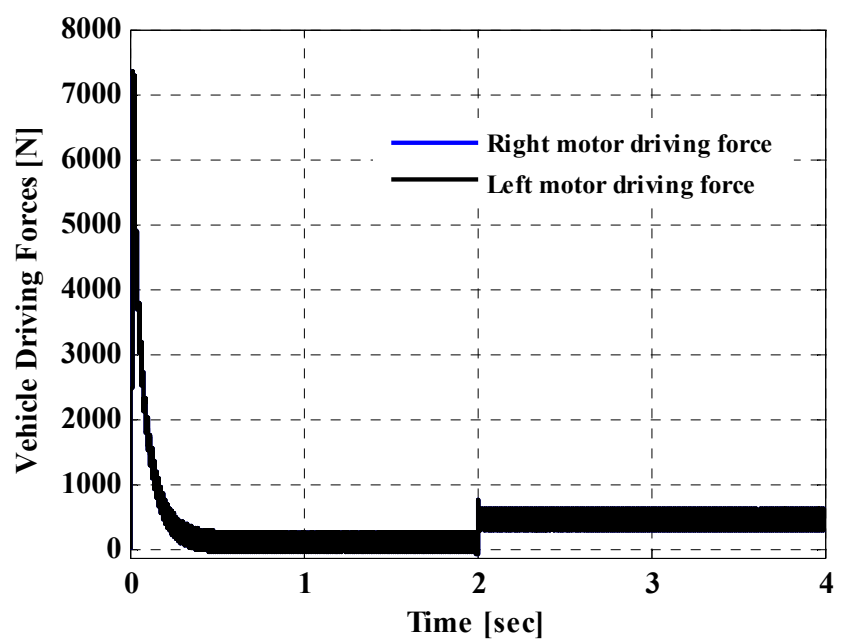

Fig. 11.3. vehicle Electromagnetique Torques.

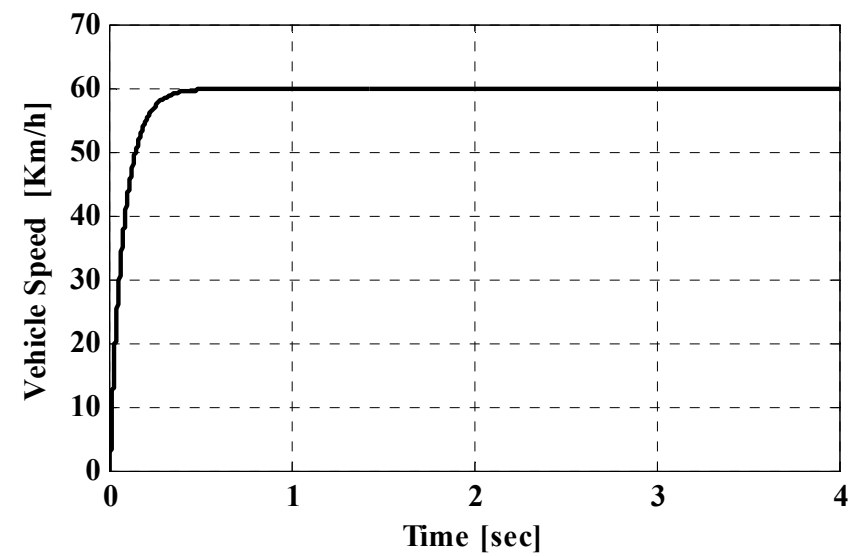

Fig. 11.4. vehicle speed variation.

Table 3. Performances of the PI \& FLC controllers in vehicle speed response

\begin{tabular}{c|c|c|c|c|c|c|c}
\hline Results & $\Delta w$ & $V_{\text {refL }}^{*}$ & $V_{\text {refR }}^{*}$ & $\alpha$ & $V h$ & $V_{w L}$ & $V_{w R}$ \\
\hline PI & 0 & 60 & 60 & 0 & 60 & 59.87 & 59.87 \\
\hline FLC & 0 & 60 & 60 & 0 & 60 & 60 & 60 \\
\hline
\end{tabular}

Table 4. Performances of the FLC and PI controllers

\begin{tabular}{c|c|c|c|c}
\hline Results & $\begin{array}{c}\text { Total vehi- } \\
\text { cle torques } \\
\left(\mathrm{T}_{\mathrm{v}}\right)\end{array}$ & $\begin{array}{c}\text { Tire torque } \\
(\text { Ttire })\end{array}$ & $\begin{array}{c}\text { Aerodynamique } \\
\text { torque } \\
(\text { Taero) }\end{array}$ & $\begin{array}{c}\text { Slope } \\
\text { torque } \\
(\text { Tslope) }\end{array}$ \\
\hline $\begin{array}{c}\text { Maximum } \\
\text { value -FLC } \\
{[\mathrm{Nm}]}\end{array}$ & 124.80 & 9.067 & 23.48 & 92.26 \\
\hline $\begin{array}{c}\text { Maximum } \\
\text { value -PI } \\
{[\mathrm{Nm}]}\end{array}$ & 195.00 & 9.067 & 93.7 & 92.26 \\
\hline $\begin{array}{c}\text { Time ap- } \\
\text { plication } \\
{[\mathrm{Sec}]}\end{array}$ & Permanent & Permanent & Permanent & 2 \\
\hline
\end{tabular}

\subsection{Case of Curved Way}

- Curved road at right side with speed of $60 \mathrm{~km} / \mathrm{h}$.

The vehicle is driving on a curved road on the right side with $60 \mathrm{~km} / \mathrm{h}$ speed. The assumption is that the two motors are not disturbed. In this case the driving wheels follow different paths, and they turn in the same direction but with different speeds.

The electronic differential acts on the two motor speeds by decreasing the speed of the driving wheel on the right side situated inside the curve, and on the other hand by increasing the wheel motor speed in the external side of the curve. The Fuzzy Logic control ensure the stability of the propulsion system by maintaining the motorization error speed equal zeros and gives a good rising time and no over tracking error too The behavior of these speeds is given by Fig. 12.3, the variation of the vehicle torques and the electromagnetic torques are illustrated in Fig. 12.4 and 12.1 and Fig. 12. 2.

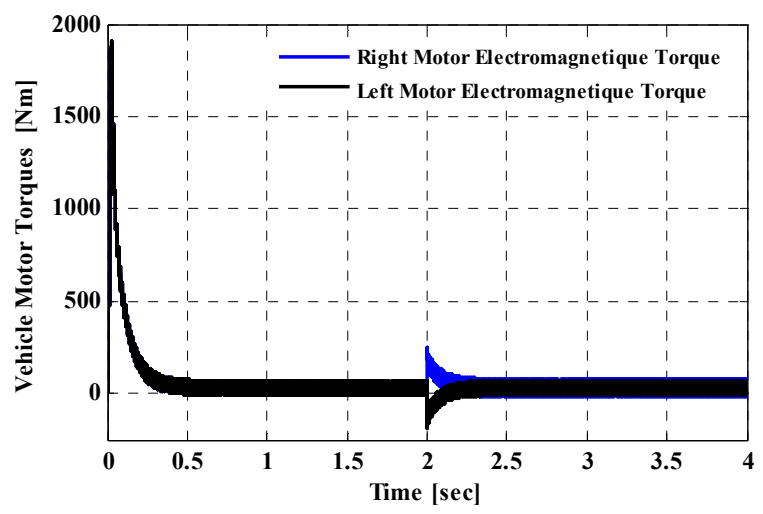

Fig. 12.1. Vehicle Electromagnetique Torques.

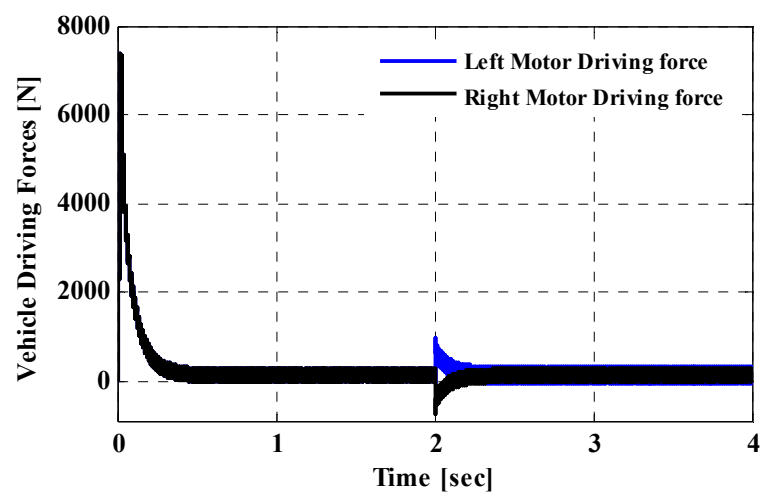

Fig. 12.2. vehicle driving force.

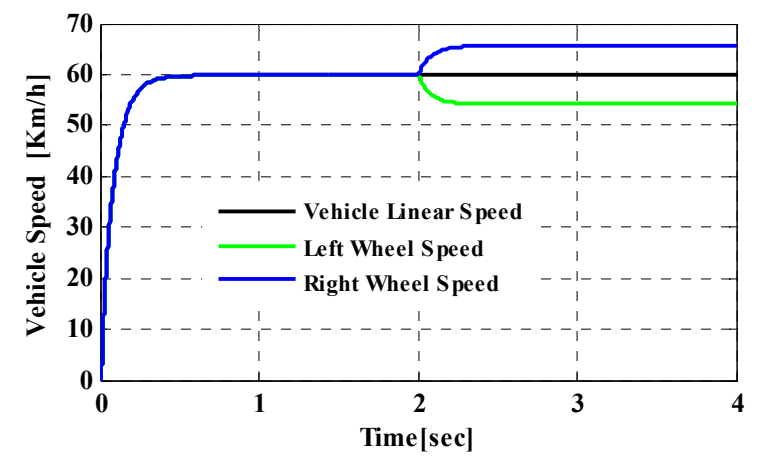

Fig. 12.3. Vehicle speed variation. 


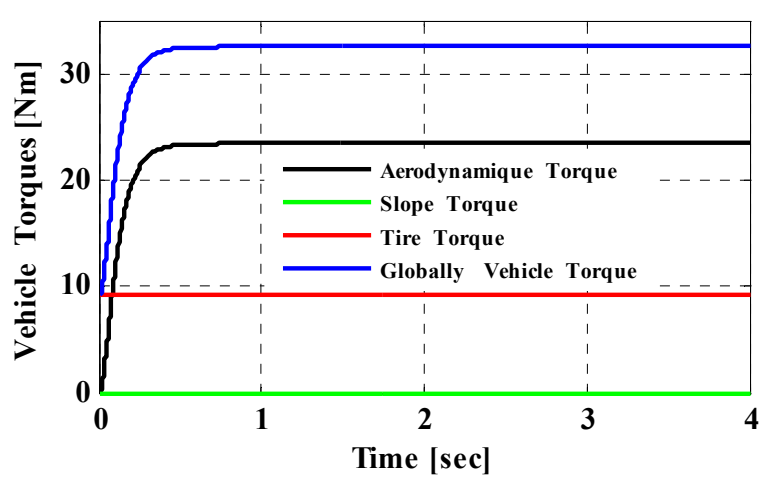

Fig. 12.4. Vehicle resistive torques.

Table 5. Performances of the FLC controller in the vehicle speed loop

\begin{tabular}{ll|c|c}
\hline \multicolumn{2}{c|}{ Results } & PI & FLC \\
\hline$\Delta v$ & {$[\mathrm{Km} / \mathrm{h}]$} & 5 & 5 \\
\hline$V_{\text {refL }}^{*}$ & {$[\mathrm{Km} / \mathrm{h}]$} & 65.74 & 65 \\
\hline$V_{\text {refR }}^{*}$ & {$[\mathrm{Km} / \mathrm{h}]$} & 54.26 & 55 \\
\hline Time curve & {$[\mathrm{Sec}]$} & 2 & 2 \\
\hline Curve angle $\alpha$ & {$\left[{ }^{\circ}\right]$} & 5.81 & 5.81 \\
\hline$V h$ & {$[\mathrm{Km} / \mathrm{h}]$} & 60 & 60 \\
\hline$V_{w L}$ & {$[\mathrm{Km} / \mathrm{h}]$} & 65.6 & 65 \\
\hline$V_{w R}$ & {$[\mathrm{Km} / \mathrm{h}]$} & 54.15 & 55 \\
\hline \multicolumn{2}{r|}{} \\
\hline
\end{tabular}

Table 6. Performances of the FLC and PI controllers on the vehicle torques response

\begin{tabular}{c|c|c|c|c}
\hline Results & $\begin{array}{c}\text { Total } \\
\text { vehicle } \\
\text { torques } \\
\text { (Tv) }\end{array}$ & $\begin{array}{c}\text { Tire } \\
\text { torque } \\
\text { (Ttire) }\end{array}$ & $\begin{array}{c}\text { Aerodynamique } \\
\text { torque } \\
\text { (Taero) }\end{array}$ & $\begin{array}{c}\text { Slope } \\
\text { torque } \\
\text { (Tslope) }\end{array}$ \\
\hline $\begin{array}{c}\text { Maximum } \\
\text { value -FLC } \\
{[\mathrm{Nm}]}\end{array}$ & 32.65 & 9.1141 & 23.444 & 0 \\
\hline $\begin{array}{c}\text { Maximum } \\
\text { value -PI } \\
{[\mathrm{Nm}]}\end{array}$ & 102.5 & 9.114 & 93.7 & 0 \\
\hline $\begin{array}{c}\text { Time appli- } \\
\text { cation [Sec] }\end{array}$ & Permanent & Permanent & Permanent & $\begin{array}{c}\text { Appli- } \\
\text { cation }\end{array}$ \\
\hline
\end{tabular}

\subsection{The Electric Vehicle Stability Against Vehicle Torque Variation Impact Way}

- The Slope torque effect on Electric Vehicle Motion Stability in Straight way

In this case and according to the formula number (7), we introduce the slope torque effect's as a very important factor in the globally vehicle resistive torque tuning parameters in the straight way slopped case's as it shown in Fig. 13.

We can obtain a table which summarises results simulated in Matlab Work Space given as follow:

According to the result obtained in Fig. number (13) and the Table (7) it's appear clearly that:

When the slope torque constitute the 80 percent of the globally resistive torque, the vehicle haven't the ability to
Table 7. Vehicle Slope torque effect

\begin{tabular}{c|c|c|c}
\hline $\begin{array}{c}\alpha^{\circ} \\
(\text { Slope } \\
\text { angle) }\end{array}$ & $\begin{array}{c}\text { Slope } \\
\text { Torque } \\
{[\mathrm{Nm}]}\end{array}$ & $\begin{array}{c}\text { Globally Vehicle } \\
\text { Resistive Torque } \\
{[\mathrm{Nm}]}\end{array}$ & $\begin{array}{c}\text { Slope Torque } \\
\text { Impact in \% }\end{array}$ \\
\hline 3 & 47.7 & 80.22 & $59.46 \%$ \\
\hline 5 & 79.43 & 111.9 & $70.98 \%$ \\
\hline 8 & 126.8 & 159.3 & $79.59 \%$ \\
\hline 10 & 158.3 & 190.7 & $83.09 \%$ \\
\hline 15 & 235.9 & 268.1 & $87.98 \%$ \\
\hline 20 & 311.7 & 343.7 & $90.68 \%$ \\
\hline
\end{tabular}

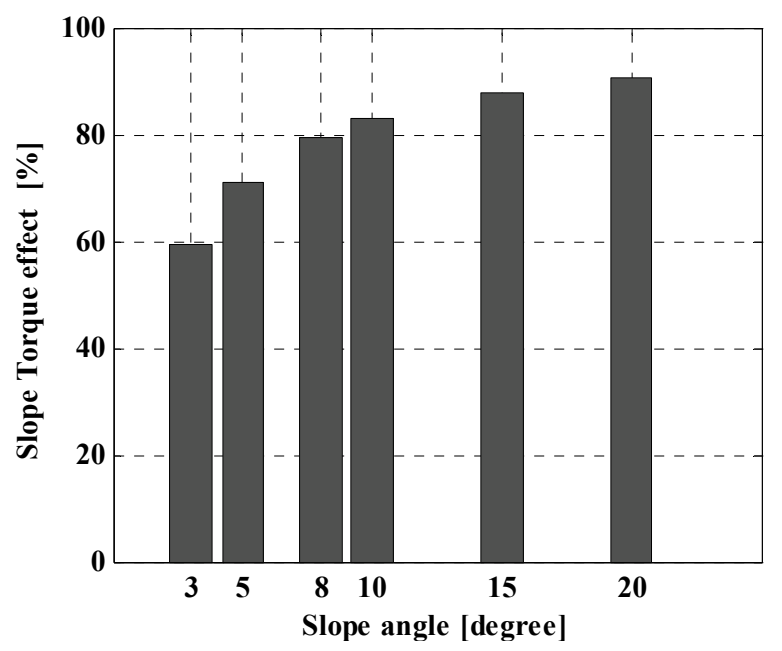

Fig. 13. vehicle slope effect on the globally vehicle torque.

climb the slope by means that the effort developed on the motor drive shaft isn't sufficient to satisfy the hall demand of the vehicle traction chain, in this situation the vehicle became instable, furthermore the power torque developed produce a high temperature around the motor drive shaft as it shown on Fig. 13 and all results are summarized in the Table 7.

-After computations we can substitute a linear formula between the vehicle torque and Slope torque this Formula is given as Follow:

$$
V_{t}=P_{1} * T_{\text {slope }}+P_{2}
$$

Where:

$V_{t}$ and $T_{\text {slope }}$ are the globally vehicle resistive torque and the Slope Torque respectively P1 and P2 are constants $\mathrm{P} 1=15.59$ and $\mathrm{P} 2=33.543$.

- The Grade angle of the Road effect on Electric Vehicle Motion Stability

According to formula 16,17 and 19 which give the vehicle linear speed right $\&$ left and the difference between them several simulations where carried in order to precise the dynamical stability state of the electric vehicle .

The Table number 8 summaries the grade angle of road effect on the Right and Left speed references variations respectively $\operatorname{VrefR}$ and $\operatorname{VrefL}$ according to the speed 
variation $\Delta V$ given by the electronic differential.

We fixes always the vehicle linear speed constant at 60 $\mathrm{km} / \mathrm{h}$ during this simulation the results of this case are shown in Table 8 and Fig. 14.

Based on the precedent formulas $(16,17,19)$ which gives the relationship between the grade angle of road and the speed references computation's, we say that when the driver turn the steering wheel in the curved road situation the angle of steer's must should be taken the values between 5 and 9 degrees in order to obtain the globally vehicle stability by means that the vehicle driver drive easily his engine when the steer's is less than 10 degrees, the second case when the steer's exceeds the 9 degrees and it's between 10 and 15 degree in this pseudo stability situation case's the vehicle driver has some difficulties to control the vehicle motion because there's an important difference between the left and the right speed reference as it shown on Fig. 14 and Table 8, finally when the steers exceeds the 15 degrees the vehicle over go the curve because there's huge difference between the right and the left speed references.

Table 8. Vehicle speed angle road effect

\begin{tabular}{c|c|c|c|c|c}
\hline $\begin{array}{c}\delta \circ \\
\text { (steering } \\
\text { angle) }\end{array}$ & $\Delta V$ & $\begin{array}{c}V h \\
\text { Vehicle linear } \\
\text { speed }\end{array}$ & $V_{\text {refL }}$ & $V_{\text {refR }}$ & $\begin{array}{c}\text { Stability } \\
\text { State }\end{array}$ \\
\hline 5 & 5 & 60 & 65 & 55 & $\mathrm{~S}$ \\
\hline 7 & 7 & 60 & 67 & 53 & $\mathrm{~S}$ \\
\hline 9 & 9 & 60 & 69 & 51 & $\mathrm{~S}$ \\
\hline 11 & 11 & 60 & 71 & 49 & PS \\
\hline 13 & 13 & 60 & 73 & 47 & PS \\
\hline 15 & 15 & 60 & 75 & 45 & PS \\
\hline 17 & 17 & 60 & 78 & 43 & IN \\
\hline 19 & 19 & 60 & 79 & 41 & IN \\
\hline 21 & 21 & 60 & 81 & 39 & IN \\
\hline 23 & 23 & 60 & 83 & 37 & IN \\
\hline 25 & 25 & 60 & 85 & 35 & IN \\
\hline
\end{tabular}

Where S ,PS and IN means :

S: Vehicle Stable

PS: Vehicle Pseudo Stability (by means the vehicle stable at $60 \%$ ).

IN: Vehicle Instable

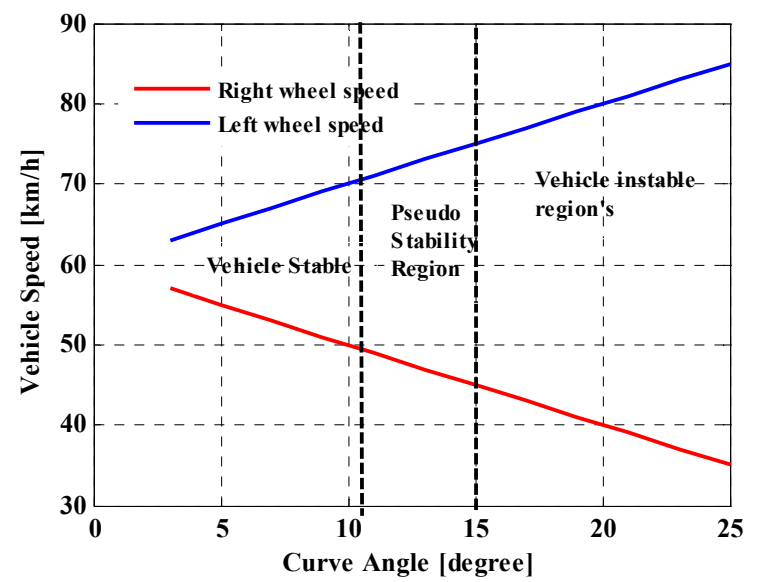

Fig. 14. vehicle angle road stability effect.

\section{Conclusion}

The research outlined in this paper has demonstrate the feasibility of an improved vehicle stability which use two independent back drive wheels for motion by using the fuzzy inference system - control .This paper proposes an 'independent machine' control structure applied to the propulsion system of Lightweight vehicle by means the small vehicle used for urban passenger transportation ensuring by the electronic differential. The results obtained by simulation show that this structure permits the realization of the robust control based on Fuzzy inference system, with good dynamic and static performances for the multi-converters/ multi-machines propulsion system. The proposed Fuzzy controller model improve the driving wheels speeds control with high accuracy either in flat roads or curved ones.The disturbances do not affect the performances of the driving motors and the control law's efficiency gives a good dynamic characteristics of the traction chain. The major advantages of a vehicle using independent wheel control are the ability to traverse steep slopes, and the ability to have larger wheels and improved load carrying and distribution of load compared to conventional vehicles of the type.

\section{Appendix}

Table 9. Electric vehicle Parameters

\begin{tabular}{c|c|r}
\hline $\mathrm{Te}$ & Motor traction torque & $247 \mathrm{Nm}$ \\
\hline $\mathrm{J}_{\mathrm{e}}$ & Moment on inertia of the drive train & $7.07 \mathrm{Kgm}^{2}$ \\
\hline $\mathrm{R}_{\mathrm{w}}$ & Wheel radius & $0.36 \mathrm{~m}$ \\
\hline $\mathrm{a}$ & Total gear ratio & 10.0 \\
\hline$\eta$ & Total transmission efficiency & $93 \%$ \\
\hline $\mathrm{M}$ & Vehicle mass & $3904 \mathrm{Kg}$ \\
\hline $\mathrm{f}_{\mathrm{e}}$ & Bearing friction coefficient & 0.001 \\
\hline $\mathrm{K}_{\mathrm{d}}$ & Aerodynamic coefficient & 0.46 \\
\hline $\mathrm{A}$ & Vehicle frontal area & $3.48 \mathrm{~m}$ \\
\hline $\mathrm{f}_{\mathrm{v}}$ & Vehicle friction coefficient & 0.01 \\
\hline$\alpha$ & Grade angle of the road & $\mathrm{rad}$ \\
\hline $\mathrm{L}_{\mathrm{w}}$ & Distance between two wheels and axes & $2.5 \mathrm{~m}$ \\
\hline $\mathrm{d}_{\mathrm{w}}$ & Distance between the back and the front wheel & $1.5 \mathrm{~m}$ \\
\hline
\end{tabular}

Table 10. Induction Motors Parameters

\begin{tabular}{c|c|c}
\hline $\mathrm{R}_{\mathrm{r}}$ & Rotor winding resistance (per phase) & $0.003 \Omega$ \\
\hline $\mathrm{Rs}$ & Stator winding resistance (per phase) & $0.0044 \Omega$ \\
\hline $\mathrm{L}_{\mathrm{s}}$ & Stator leakage inductance (per pohase) & $16.1 \mu \mathrm{H}$ \\
\hline $\mathrm{L}_{\mathrm{m}}$ & Magnetizing inductance (per phase) & $482 \mu \mathrm{H}$ \\
\hline $\mathrm{L}_{\mathrm{r}}$ & Rotor leakage inductance (per phase) & $12.9 \mu \mathrm{H}$ \\
\hline $\mathrm{f}_{\mathrm{c}}$ & Friction coefficient & 0.0014 \\
\hline $\mathrm{P}$ & Number of poles & 4 \\
\hline $\mathrm{Vh}$ & Vehicle linear speed & \\
\hline
\end{tabular}


Table 11. Symbols, Designation and Units

\begin{tabular}{|c|c|c|}
\hline $\begin{array}{l}\text { Sym- } \\
\text { bols }\end{array}$ & Nomenclature & units \\
\hline $\mathrm{J}_{\mathrm{e}}$ & Moment of inertia of the drive train & Kg.m $\mathrm{m}^{2}$ \\
\hline $\mathrm{J}_{\mathrm{v}}$ & Vehicle inertia & Kg.m $\mathrm{m}^{2}$ \\
\hline $\mathrm{T}_{\mathrm{em}}$ & Electromagnetic torque & $\mathrm{Nm}$ \\
\hline $\mathrm{T}_{\mathrm{v}}$ & Vehicle torque & $\mathrm{Nm}$ \\
\hline $\mathrm{T}_{\text {slope }}$ & Slope torque & $\mathrm{Nm}$ \\
\hline $\mathrm{T}_{\text {aero }}$ & Aerodynamique torque & $\mathrm{Nm}$ \\
\hline $\mathrm{T}_{\text {tire }}$ & Tire torque & $\mathrm{Nm}$ \\
\hline $\mathrm{T}_{\text {in }}$ & Inertia vehicle torque & $\mathrm{Nm}$ \\
\hline $\mathrm{N}_{\mathrm{red}}$ & Report of speed gear & $\%$ \\
\hline$\eta$ & Transmission efficiency & $\%$ \\
\hline $\mathrm{L}_{\mathrm{w}}$ & Distance between two wheels & $\mathrm{m}$ \\
\hline $\mathrm{d}_{\mathrm{w}}$ & Distance between the back and the front wheel & $\mathrm{m}$ \\
\hline$\rho$ & Air density & \\
\hline S & Frontal vehicle surface & $\mathrm{m}^{2}$ \\
\hline $\mathrm{C}_{\mathrm{x}}$ & Aerodynamic drag coefficient & \\
\hline $\mathrm{g}$ & Gravitational acceleration & $\mathrm{N} / \mathrm{m}$ \\
\hline$K_{b}$ & Choice of direction coefficient & $\mathrm{Rad} / \mathrm{sec}$ \\
\hline$\Delta W$ & $\begin{array}{c}\text { Angular speed variation given by electronic } \\
\text { differential }\end{array}$ & $\mathrm{Rad} / \mathrm{sec}$ \\
\hline$W_{r R}$ & Right wheel angular speed & $\mathrm{Rad} / \mathrm{sec}$ \\
\hline$W_{r L}$ & Left wheel angular speed & $\mathrm{Rad} / \mathrm{sec}$ \\
\hline$W_{m R}^{*}$ & Right wheel angular speed of reference & $\mathrm{Rad} / \mathrm{sec}$ \\
\hline$W_{m L}^{*}$ & Left wheel angular speed of reference & $\mathrm{rad}$ \\
\hline$\delta$ & Real angle wheel curve's & $\mathrm{rad}$ \\
\hline$\beta$ & Vehicle slip angle & $\mathrm{rad}$ \\
\hline IFOC & Indirect Field oriented Control & \\
\hline FLC & Fuzzy Logic Control & \\
\hline MR & The Right Motor & \\
\hline ML & The Left Motor & \\
\hline PI & Proportional Integral & \\
\hline
\end{tabular}

\section{References}

[1] A.Poursamad, M. Montazeri. "Design of GeneticFuzzy Control Strategy for Paralled Hybrid Electric Vehicles," Control Engineering Practice, doi:10.1016/ j.conengprac. 2007. 10. 003.

[2] Y. Pien Yang, C.Pin Lo "Current Distribution Control of Dual Directly Driven Wheel Motor for Electric Vehicles," Control Engineering Practice, Vol.No.16, 2008. pp.1285-1292.

[3] Hartani.K,Bourahla.M. Miloud.Y,'Electric Vehicle Stability Improvement Based on Anti-Skid Control Using Behaviour Model Control," Electro motion Cluj Napoca, Vol.14, Part4, Pages209-171.

[4] A.Nasri,A.Hazzab, I.K.Bousserhane,S.Hadjeri,P.Sicard, "Two Wheel Speed Robust Sliding Mode Control For Electric Vehicle Drive," Serbian Journal of Electrical Engineering, Vol. 5, No.2, Nov., 2008, pp.199-216.

[5] B.Allaoua, A.Laoufi, A.Nasri, "Intelligent Controller design of DC motor speed control based on Fuzzy Logic -Genetic Algorithms Optimisations," Leonardo
Journal of Sciences, Issue 13, Dec., 2008, pp.90-102.

[6] A.Ghani.Aissaoui, M.Abid, H.Abid, A.Tahour, A.Zeblah, "A Fuzzy logic Controller for Synchronous machine," Journal of electrical engineering, Vol.58, No.5, 2007, 285-290.

[7] H.Rehman, R.Dhaoudi, “A fuzzy Learning-Sliding Mode Controller for Direct Field Oriented Induction Machines," Neurocomputing, Elseiver, Vol.71, 2008, pp.2693-2701.

[8] A.Nasri, A.Hazzab, I.K.Bousserhance, S.Hadjeri, P.Sicard, "Fuzzy-Sliding Mode Speed Control for Two Wheels Electric Vehicle Drive," Korean Journal of Electrical Engineering \& Technology, Vol.4, No.4, pp.499-509, 2009499.

[9] H Il.-SongKimA, "Non Linear State of Charge Estimator for Hybrid Electric Vehicle Battery," IEEE Transactions, Vol.23, No.4, jul., 2008, pp.2027-2034.

[10] A.Tahour, Hamza, Abid, A.Aissaoui, "Speed Control of Swi-ched Reluctance Motor Using fuzzy Sliding Mode," Advances in Electrical and Computer Engineering, Vol.8.15, Number 1(29), 2008.

[11] A.Tahour, Hamza, Abid, A.Aissaoui, "Speed Control of Switched Reluctance Motor Using fuzzy Sliding Mode," Advances in Electrical and Computer Engineering, Vol.8.15, Number 1(29), 2008.

[12] Gang Shi,Yuanwei Jing, Aidong Xu, "Study and Simulation of Based fuzzy logic parallel Hybrid Electric Vehicles," Proceeding of the sixth international Conference on intelligent System Design and Applications (ISDA 06). IEEE2006.

[13] C.Y.Chen, T.Hseng S.Li, Y. C.Yeh, "EP-based kinematic control and adaptive fuzzy sliding-mode dynamic control for wheeled mobile robots," Information Sciences 179 (2009) 180-195.

[14] A. Hazzab, I. K. Bousserhane, M. Kamli and M. Rahli: "New Adaptive fuzzy PI-Sliding Mode Controller for Induction Machine Speed Control," Third IEEE International Conference on Conference on Systems, Signals \& Devices SSD'05, Tunisia, (2005).

[15] Keyun.C, Alain.B,and Walter.L, "Energetic Macroscopic Representation and inversion-based control Application to an Electric Vehicle With An Electrical Differantial," Journal of Asian Electric Vehicles, Vol.6, No.1, June 2008, pp.1097-1102.

[16] B.Allaoua, A.Abderahmani, B.Gasbaoui,A.Nasri, "The Effeciency of particle Swarm Opti;iwqtion Applied On Fuzzy Logic DC Motor Speed Control," Serbian Journal of Electrical Engineering , Vol.5, No.2, november 2008, pp247-262.

[17] J. A.Haddoun, M.Benbouzid, D.Diallo, "Modeling, Analysis, and Neural Network Control of An EV Electrical Differantial", IEEE Transactions, Vol.55, No.6, June 2008, pp.2286-2294.

[18] Y.Pin.Yang,C.Pin.Lo, "Current Distribution Control of Dual Directly Driven Wheel Motors for Electric Vehicles," Control Engineering Practice,Vol.16, 2008, pp.1285-1292.

[19] Larminie, "Electric Vehicle Technology Explained," 
Edited by John Wiley and John Lowry, England, 2003.

Nasri Abdelfatah was born in 1978 at Bechar-Algeria, he's received the electrical engineering diploma from Bechar Center University-Algeria in 2002, and the Master degree from the University of Sciences and Technology of Oran (USTO),Algeria in 2006. Currently he is an assistant teacher at Bechar University. From 2007 right now he's preparing his Phd degree in Electric vehicle propulsion system control.

Hazzab Abdeldjabar received the state engineer degree in electrical engineering in 1995 from the University of Sciences and Technology of Oran (USTO), Algeria, the M.Sc. degree from the Electrical Engineering Institute of the USTO in 1999, and the Ph.D. degree from the Electrical Engineering Institute of the USTO in 2006. He is currently professor of electrical engineering at University of Bechar, Bechar, Algeria.

His research interests include power electronics, electric drives control, and artificial intelligence and there applications.

Ismail Khalil Bousserhane received the B.Sc. degree in electrical engineering from the Electrical Engineering Institute of the University Center of Bechar in 2000, the M.Sc. degree in electrical engineering from the University of Sciences and Technology of Oran (USTO), Algeria, in 2003 and the Ph.D. degree from the Electrical Engineering Institute of USTO in 2008. He is currently an assistant professor of electrical engineering at University of Bechar, Bechar, Algeria.

His research interests include modern control techniques and their application in electric drives control.
Hadjeri Samir received the Master degree in electrical engineering from the University of Laval, Quebec, Canada, in 1990, and Ph.D. degree from the University of Sidi BelAbbes, Algeria, in 2003. From 1991 to 2004 he was at the Faculty of Science Engineering, Department of Electrical Engineering, Sidi Bel-Abbes and Algeria, as a teaching member.

His research interests include high voltage direct current and power system analysis.

Pierre Sicard received the Master degree in industrial electronics from the University of Quebec in TroisRivieres, Trois-Rivieres, Canada, in 1990, and a Ph.D. degree in electrical engineering from Rensselaer Polytechnic Institute, Troy NY, USA in 1993. He is professor in electrical and computer engineering at University of Quebec in Trois-Rivieres where he is director of the Research group on industrial electronics.

His research interests include the macroscopic energetic Representation, multi-drives control and the rollingunrolling system control. 